\title{
Corneal rust removal by electric drill Clinical trial by comparison with manual removal
}

\author{
NICHOLAS BROWN, RICHARD CLEMETT, AND RODNEY GREY \\ From the Department of Clinical Ophthalmology, Moorfields Eye Hospital, London
}

The rusty ferrous corneal foreign body is a common reason for attendance at casualty departments. Improved efficiency in the treatment of this condition would reduce both the clinician's time spent with each patient and the patient's time off work.

Rust has a toxic effect on the corneal stroma, and if left in situ, after removal of the foreign body the rust-stained tissue undergoes necrosis and sloughs. Early removal of all rust without damage to the cornea is therefore the aim of any form of treatment.

Medical treatment in the form of local Desferrioxamine has been used in the hope of removing rust without causing any stromal destruction. A clinical trial to test Desferrioxamine against surgical (manual) removal, and against expectant treatment (McGuinness and Knight-Jones, 1968), showed that surgical removal was significantly better than Desferrioxamine, and that Desferrioxamine was significantly better than expectant treatment. Other studies of Desferrioxamine (North, 1970; Valvo, 1967; and Wise, 1966) demonstrated the usefulness of this treatment, but have not shown it to be superior to surgical treatment.

Rapid complete surgical removal with minimal trauma to the cornea can at present be expected to offer the best form of treatment. The electric drill was introduced for this purpose and has been improved in design in recent years. The first description of an electric drill for corneal rust removal appears to be that of Witzeman (1936). Other instruments have been described (Hardesty, 1965; Soukup, 1968; and Worst, 196r). All these instruments rotate dental burrs.

The manually rotated dental burr has also been advocated (Grossmann, 1950), and was the method in use at this hospital before the introduction of an electric drill.

Before the drill is applied to the cornea, the foreign body needs to be lifted off by a Bowman needle, but syringe needles have been advocated for their convenience (Applebaum, 1943; and Harding, 1943). A disposable syringe needle is now preferred.

Address for reprints: N. Brown, Department Clinical Ophthalmology, Moorfields Eye Hospital, City Road, London ECIV 2PD
In spite of the number of corneal electric drills described, there appears to have been no clinical trial of their performance. A study is now reported in which electric drill rust removal is compared with manual removal. Design criteria for electric drills are also considered.

\section{Materials and methods}

\section{INSTRUMENTS}

After experience with a prototype instrument, a new slim electric drill (Fig. I) which can be held in the hand like a pencil has been built to our design. It has a spring friction chuck to hold dental burrs and is operated by light finger pressure from any side on a ring. A brake is incorporated so that the drill stops rotating very soon after the operator's finger is lifted, which is considered to be a useful safety feature.

The drill is advanced obliquely to the eye so that the side and not the pole of the dental burr works on the cornea. In this position the operator has the best control of the cutting pressure and of the depth of excavation of the cornea. For this reason a straight drill is better than one with an angle between the handle and the axis of the drill shaft.

\section{SELECTION OF PATIENTS}

Patients were selected from those making their first attendance at the casualty department at Moorfields Eye Hospital, without having received treatment elsewhere. All patients included had significant corneal rust with or without the ferrous foreign body still present. Patients with insignificant corneal rust were excluded as it was considered that they would soon improve with either form of treatment and so dilute the result of the trial.

Altogether 121 patients entered the trial, of whom 64 received electric drill treatment, and 57 manual treatment.

\section{CONDUCT OF THE TRIAL}

The doctor who made the decision to include the patient in the trial did not himself perform any treatments, but gave each patient an envelope coritaining a card on which was printed either 'Drill' or 'Manual'. The patient was then treated in a separate room by one of the three authors according to the written instruction. 


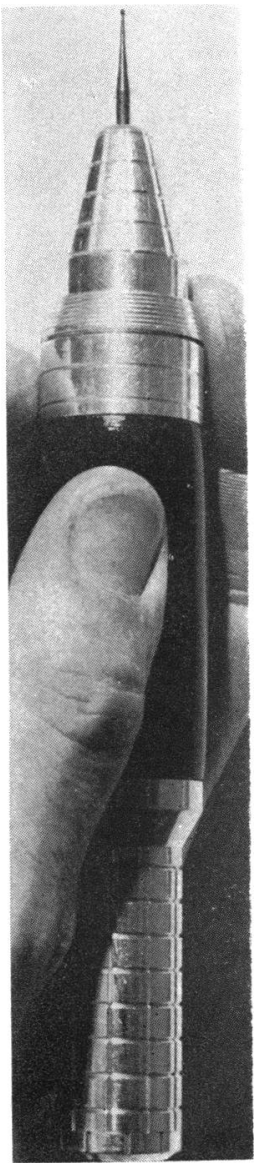

FIG. I Hand held electric drill with dental burr

The patients were instructed to return each day for follow-up until their condition had healed. They were examined at follow-up by the doctor who had first seen them and who was unaware which treatment they had received. If he considered that further rust removal was indicated, the patient again received the same method of treatment as on the first occasion.

A brief proforma was used for each examination. This included the patient's name and study number, number of attendances, presence of pain, drawing of corneal rust, drawing of epithelial lesion, and record of stromal oedema and anterior chamber activity.

\section{METHOD OF TREATMENT}

\section{Manual}

Manual treatment is conducted in a manner which is traditional in this hospital. The eye is anaesthetized with Amethocaine drops I per cent. The patient is seated at the slit lamp and the ferrous foreign body, if present, is lifted off with a $40 \mathrm{~mm} \times 0.8 \mathrm{~mm}$ disposable syringe needle. A sterile dental burr is then held between the thumb and index finger and rotated against the cornea. The eye is treated with Hyoscine drops $\frac{1}{4}$ per cent, Oc. Chloramphenicol I per cent and protected by a pad and knitted shield.

\section{Electric drill}

The patient is prepared as for manual removal and seated at the slit lamp. The ferrous foreign body is lifted off and the dental burr applied by the electric drill. Drilling is continued until all the rust stain is removed. Medicaments and padding are applied as above.

\section{Results}

The results are presented in the Table. The smaller rust rings were easily removed by either manual or electric drill treatments. Large deeply infiltrated rust rings were difficult to remove completely by manual rotation of the dental burr. The more central parts of the rust ring were in soft necrotic tissue, that were easy to remove, but the peripheral part of the ring was found to be in firm stromal tissue, which was not easy to remove. Persistence with manual removal at this point caused an irregular breakup of the crater. This led to incomplete removal in several patients (Table), which resulted in further treatment being needed at their next attendance when the rust ring had increased in diameter.

There was no difficulty in removing the complete rust ring at the first treatment using the electric drill. The drill cut cleanly in firm cornea and under slit-lamp control it was easy to remove all the rust and to avoid removing healthy cornea beyond the ring. This left a smooth crater (Figs 2-4), which contrasted with the irregular crater after manual removal. With slit-lamp control, the electric drill was found to be entirely safe and there were no instances of unintentional corneal excavation.

Table Results of clinical trial comparing patients treated manually with those treated with an electric drill

\begin{tabular}{|c|c|c|}
\hline Details & Drill & Manual \\
\hline $\begin{array}{l}\text { Total number of patients treated } \\
\text { Mean treatment time (seconds) } \\
\text { Percentage of patients requiring } \\
\text { second treatment } \\
\text { Mean duration of attendance } \\
\text { (days) } \\
\text { Mean persistence of pain (days) } \\
\text { Mean persistence of rust (days) } \\
\text { Mean epithelial healing time } \\
\text { (days) } \\
\text { Mean time for clearance of } \\
\text { stromal infiltrate (days) }\end{array}$ & $\begin{array}{l}64 \\
70 \\
0 \\
3 \cdot 18 \\
0 \cdot 02 \\
0 \cdot 10 \\
2 \cdot 45 \\
1 \cdot 43\end{array}$ & $\begin{array}{r}57 \\
162 \\
9 \cdot 4 \\
3 \cdot 84 \\
0 \cdot 64 \\
0 \cdot 83 \\
2 \cdot 87 \\
1 \cdot 90\end{array}$ \\
\hline
\end{tabular}


FIG. 2 Corneal macrophotograph of ferrous foreign body in situ

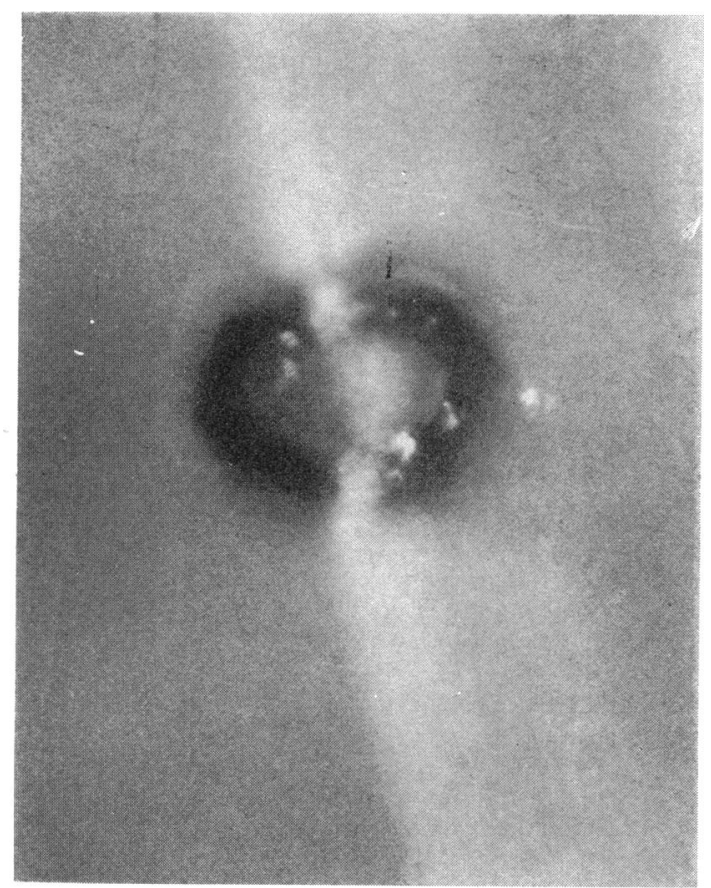

FIG. 3 Same eye. The ferrous foreign body has been lifted off leaving rust ring

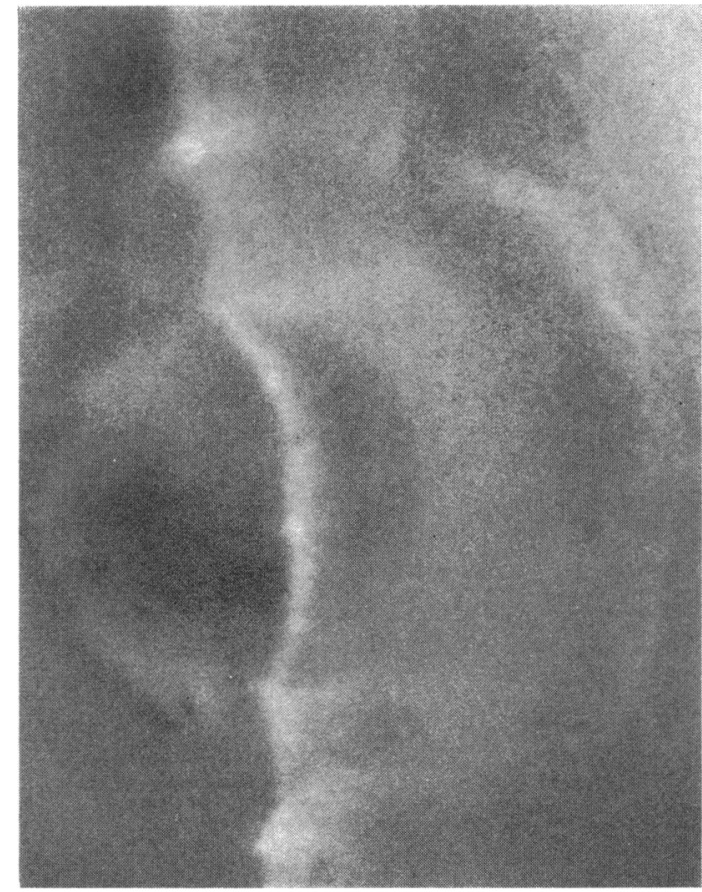

FIG. 4 Same eye. The rust ring has been removed by electric drill. The slit beam shows a smooth-sided crater

The numerical results (Table) show that the drill was better for every measurement, but in some parameters with a poor degree of statistical significance.

No patient who was treated with the electric drill required a second treatment, whereas five patients $(9 \cdot 4$ per cent) of those manually treated required a second treatment.

The mean duration of attendance was less for the patients treated by electric drill ( $3 \cdot 18$ days compared with 3.84 days, which is barely significant $(P=0.2))$. Persistence of pain was significantly shorter in the group treated by electric drill (mean 0.02 days compared with 0.64 days for manual removal). The time for epithelial healing was not significantly less in the drill group $(\mathrm{P}=0.4)$. The electric drill treatment took less than half as long as the manual treatment.

\section{Discussion}

The present study shows that corneal rust removal by electric drill is more efficient than manual removal. McGuinness and Knight-Jones (1968) showed manual removal to be better than treatment by Desferrioxamine; they concluded that Desferrioxamine should still be used if proper facilities for manual removal were not available. Both elec- 
tric drill removal and manual removal should be performed at the slit lamp, so where this instrument is not available Desferrioxamine should still be considered.

\section{Conclusion}

The dental burr rotated by an electric drill is the quickest, safest, and most precise form of treatment for corneal rust rings. It enables complete removal of the corneal rust at a single treatment and leaves a smooth crater that is no larger than the original rust ring. Pain relief is more rapid after electric drill removal; this is probably related to the com- plete removal of the rust. Epithelial and stromal healing are marginally faster than after manual removal and the patients' duration of attendance is less.

The ideal drill is a slim straight instrument, which rotates dental burrs and is operated by a light finger pressure. A brake which stops drill rotation on lifting the finger is a useful safety feature.

We should like to thank Professor Barrie Jones for his advice and encouragement in initiating this study and the staff of the Dental Workshop at University College Hospital for their engineering skill.

\section{References}

APplebaum, A. (1943) Arch. Ophthal. (Chicago), 30, 262

GrossmanN, E. E. (1950) Amer. F. Ophthal., 33, 293

HARDESTY, H. H. (1965) Ibid., 60, 526

HARDING, G. F. (1943) Arch. Ophthal. (Chicago), 29, 134

MCGUINNESS, R., and KNIGHT-JONES, D. (1968) Brit. F. Ophthal., 52, 777

NORTH, P. J. (1970) Ibid., 54, 498

soukuP, F. (1968) Cs. Oftal., 24, 146

valvo, A. (1967) Amer. F. Ophthal., 63, 98

wISE, J. B. (1966) Arch. Ophthal. (Chicago), 75, 698

WITZEMAN, L. A. (1936) Ibid., 16, 857

wORST, J. G. F. (1961) Amer. F. Ophthal., 52, 122 